\title{
Prophylactic versus Therapeutic Amnioinfusion for Oligo Hydramnios in Labour
}

\author{
Authors \\ Dr Shabnam Phuleman ${ }^{1}$, Dr Rashmi Verma ${ }^{2}$, Dr Shaesta Iqbal ${ }^{3}$ \\ ${ }^{1}$ PGT $3{ }^{\text {RD }}$ year Department of obstetrics \& Gynaecology, $\mathrm{KMCH}$ \\ ${ }^{2}$ Associate Professor, Department of Obstetrics \& Gynaecology, KMCH \\ ${ }^{3}$ PGT 3rd year Department of Obstetrics \& Gynaecology, KMCH
}

\section{Introduction}

Amnioinfusion was introduced by Miyazaki and Taylor (1983) who infused saline through an intrauterine pressure catheter in labouring women who had either variable or prolonged decelerations attributed to cord entrapment.

Oligohydramnios is defined as where liquor amnii deficient in amount to the extent of less than $200 \mathrm{ml}$ at term. Sonographically, it is defined when the maximum vertical pocket of liquor is less than $2 \mathrm{~cm}$ or Amniotic fluid Index (AFI) is less than $5 \mathrm{~cm}$. AFI between $5-8 \mathrm{~cm}$ is borderline Oligohydraminos.

Adequate amount of amniotic fluid is required for good outcome of labour and this is attributed to mechanical cushions of umbilical cord.

Based on many reports, transvaginal amnioinfusion has been extended to their clinical areas (Dad,2016)

\section{These Include}

(a) PROPHYLACTIC amnioinfusion in women with Oligohydraminos, with prolonged rupture of membranes.

(b) Attempts to dilute or wash out thick meconium (c) THERAPEUTIC amnioinfusion in patients with variable or prolonged decelerations, associated with umbilical cord compression.

\section{Aim \& Objective}

The objective of this article is to compare the effects of prophylactic\& therapeutic amnioinfusion in oligohydraminos in labour.

\section{Material and Method}

Study Design - It is a hospital based randomized trial.

Study Place- Department of Obstetrics \& Gynaecology, KMCH, Katihar, Bihar.

Study Period - 1st Feb 2018 to 1st Feb 2019 with a minimum period of 6 months follow up.

Study Population- Sample size of 240 pregnant patients attending emergency of Obstetrics and Gynaecology department of $\mathrm{KMCH}$ were selected. Women were divided into two groups of (120) each.

Group A - Prophylactic amnioinfusion were administered in group of patient admitted with oligohydraminos with prolonged rupture of membrane and attempts to dilute or wash out thick 
meconium.

Group B - Therapeutic amnioinfusion were administered in patients admitted with variable or prolonged decelerations of fetal heart rate associated with umbilical cord compression.

\section{Result}

240 patients were included in the study after inclusion and exclusion criteria. 120 patients were allotted to each group.

Proportion of vaginal delivery rates higher in both but not significant.

No differences were found in rate of caesarean section.

\section{Procedure}

Transcervical amnioinfusion (done when the patients is in labour) following spontaneous rupture of membranes, an intrauterine catheter or foleys catheter or simple rubber catheter or nasogastric tube is introduced transcervically within the hind water.

Fluid bottle is connected to the catheter by an infusion set. The solution is infused by gravity or infusion.

Usually $500 \mathrm{ml}$ of normal salineis instilled within $30 \mathrm{minutes}$ followed by $500 \mathrm{ml}$ slowly $(3 \mathrm{ml} / \mathrm{min})$. Amnioinfusion is stopped after infusion of $1000 \mathrm{ml}$ or delivery imminent or complication arises.

In variable deceleration, a bolus amount of $250 \mathrm{ml}$ is instilled in 20-60 $\mathrm{min}$ followed by $10-20$ $\mathrm{ml} / \mathrm{min}$ upto $600 \mathrm{ml}$ or till the variable deceleration passes off.

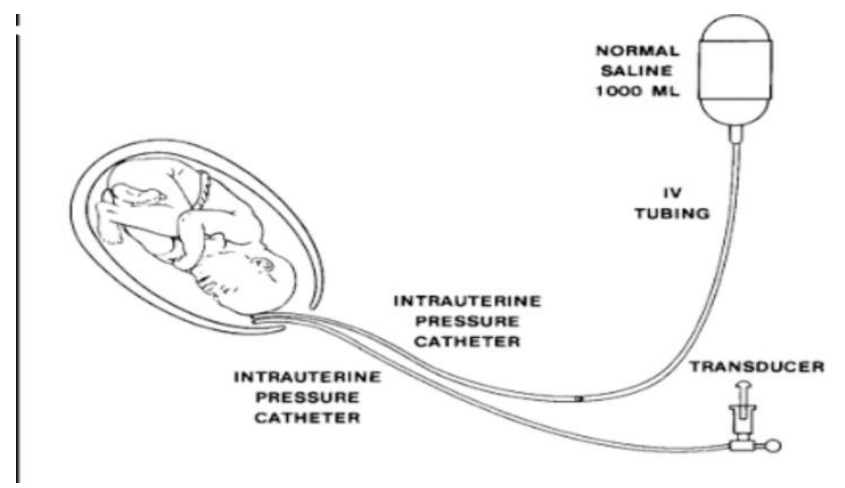

Table-1

\begin{tabular}{|l|l|l|}
\hline Mode of delivery & Prophylactic & Therapeutic \\
\hline NVD & $110(91.7 \%)$ & $105(87.5 \%)$ \\
\hline LSCS & $4(3.3 \%)$ & $11(9.2 \%)$ \\
\hline FORCEPS & $6(5.0 \%)$ & $4(3.3 \%)$ \\
\hline TOTAL & 120 & 120 \\
\hline
\end{tabular}

Table 2 Complications associated with amnioinfusion from a survey of 186 obstetrical units

\begin{tabular}{|l|c|}
\hline Complication & $\begin{array}{c}\text { No of } \\
\text { centres (\%) }\end{array}$ \\
\hline Uterinehypertonus & $27(14)$ \\
\hline Abnormal fetal heart rate tracing & $17(9)$ \\
\hline Chorioamnionitis & $7(4)$ \\
\hline Cord prolapse & $5(2)$ \\
\hline uterine rupture & $4(2)$ \\
\hline Maternal cardiac Respiratory compromise & $3(2)$ \\
\hline Placenta abruption & $2(1)$ \\
\hline Maternal Death & $2(1)$ \\
\hline
\end{tabular}

\section{Discussion}

Prophylactic amnioinfusion is indicated in women with Oligohydraminos, associated with prolong rupture of membrane and attempt to dilute or wash out thick meconium. Therapeutic amnioinfusion is used in the treatment of variable or prolonged decelerations of fetal heat rate associated with umbilical cord compression.

\section{Contraindications}

1. APH

2. Severe preeclampsia

3. Twin pregnancy

4. Classical caesarean section

5. Maternal medical condition - cardiac or pulmonary diseases.

\section{Conclusions}

- There appears to be no advantage of prophylactic amnioinfusion over therapeutic amnioinfusion carried out only when fetal heart deceleration or thick meconium staining of liquor occur.

- There were no differences in caesarean section rates,perinatal outcome, NICU admission rate, apgar score at 1 and $5 \mathrm{~min}$

- Prophylactic and therapeutic 
amnioinfusion both have definite role in decreasing the sequel of oligohydramnios when used for the correct indications.

\section{Bibliography}

1. Miyazati FS. Taylor NA: Saline amnioinfusion for relief of variable or prolonged decelerations. Am J Obster Gynacol 146.670. 1983

2. Hofmeyr GJ, Lawrie, TA: Amnioinfusion for potential or suspected umbilical cord compression in labour. Cochrane Database Syst Rev J: CD000013,2012

3. Hofmeyr GJ, $\mathrm{Xu} \mathrm{H}$, EKe AC: Amnioinfusion for meconium stained liquor in labour, Cochrane Database Syst Rev 1: CD000014,2014

4. Macri CJ, Schrimmer DB, Leung A, et al: Prophylactic amnioinfusion improves outcome of pregnancy complicated by thick meconium and Oligohydraminos. Am J Obstet Gynecol 167:117,1992.

5. Miyazaki FS, Nevarez F: Saline infusion for relief of variable decelerations. Am J Obster Gynecol153:301, 1985

6. Owen J, Henson BV, Hauth JC: A randomized study of saline solution amnioinfusion. Am J Obstet Gynecol 162:1146, 1990. 